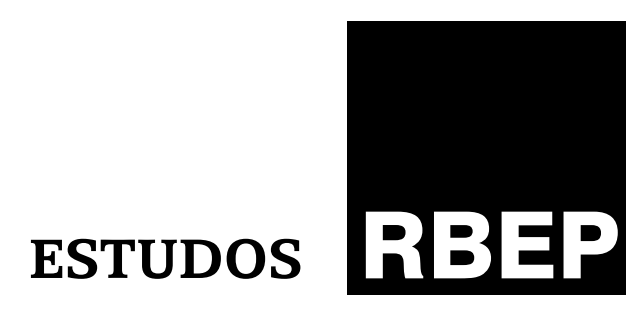

\title{
A presença dos estudantes indígenas nas universidades estaduais do Paraná: trajetórias e pertencimentos ${ }^{*}$
}

Wagner Roberto Amaral

Tânia Maria Baibich-Faria

\section{Resumo}

Analisa as trajetórias dos estudantes indígenas nas universidades estaduais do Paraná, ingressantes pelo Vestibular dos Povos Indígenas. Demonstra que a permanência desses sujeitos no ensino superior somente se faz possível mediante a efetivação de um duplo pertencimento acadêmico e étnico-comunitário. Resultado de pesquisa realizada junto aos acadêmicos indígenas, reconhece o ineditismo da experiência paranaense iniciada nesta década e sinaliza sua consolidação por meio da efetiva atuação do Estado, das universidades públicas e das comunidades indígenas.

Palavras-chave: ensino superior; ações afirmativas; povos indígenas.

* Este texto foi apresentado na 33a Reunião da Associação Nacional de Pós-Graduação e Pesquisa em Educação (ANPEd), no GT21 - Educação e Relações Étnico-raciais, realizada em Caxambu-MG, de 17 a 20 de outubro de 2010. 


\section{Abstract \\ The presence of indigenous students in the Parana State Universities: trajectories and belongings}

This study examines the trajectories of indigenous students at the Universities of Parana State, entering by the Indigenous Peoples Admission Test (vestibular), which attempts to demonstrate the permanence of these subjects in higher education is made possible only through effective implementation of a dual academic belonging and ethnic-communitarian. Result of a research carried out with indigenous graduate students, this article recognize the uniqueness of the experience of Parana began in this decade and signals its consolidation through the effective action of the State, the public universities and the leaders and indigenous communities.

Keywords: higher education; affirmative actions; indigenous peoples.

O presente trabalho evidencia que a permanência dos estudantes indígenas ingressantes na universidade somente se faz possível mediante a efetivação de um duplo pertencimento acadêmico e étnico-comunitário. A construção da condição desse duplo pertencimento, árdua e em permanente estado de desequilibração, é devida tanto ao mérito próprio do acadêmico indígena quanto ao apoio familiar e à expectativa de sua comunidade de origem. O Estado, nesse processo, avançou na inédita implementação do ingresso específico e diferenciado, limitando, porém, sua tarefa nessa ação, uma vez que a permanência - vácuo invisível, mas concreto - se dá pelas condições de afirmação dos próprios sujeitos e de seus grupos de origem.

A constituição desses sujeitos e as experiências, trajetórias e relações que passam a estabelecer na mediação entre universidade, sua comunidade de origem e seu grupo étnico tornam-se fontes de instigadora inspiração para o trabalho investigativo empreendido para a elaboração da pesquisa que gera este artigo.

A presença dos acadêmicos indígenas nas universidades públicas se constitui um fenômeno recente no Brasil, localizado principalmente na última década, decorrente da progressiva ampliação da escolarização de crianças, jovens e adultos em terras indígenas. Apresenta-se contextualizado mediante o reconhecimento da educação escolar indígena na Lei de Diretrizes e Bases da Educação Nacional de 1996, no Plano Nacional de Educação de 2001 e nas Diretrizes Nacionais da Educação Escolar Indígena no Brasil, bem como associado às discussões e experiências de 
implantação das cotas para estudantes negros oriundos de escolas públicas e indígenas nas universidades públicas.

A aprovação da Lei Estadual no 13.134, de 18 de abril de 2001, garantindo, ineditamente no País, vagas suplementares nas universidades e faculdades estaduais aos povos indígenas do Paraná, e sua implementação através do Vestibular dos Povos Indígenas a partir do ano de 2002 provocaram intensas reflexões e problematizações acerca da trajetória de acesso e permanência dos indígenas nas Instituições de Ensino Superior (IES) públicas.

Inicialmente garantidas três vagas anuais em cada universidade estadual, esse número foi ampliado para seis no ano de 2006, sendo que, em 2005, aderiu a esse processo a Universidade Federal do Paraná, com a oferta atual de dez vagas por ano. Nessa ocasião, nem as IES públicas do Paraná, tampouco os indígenas como principais sujeitos desse processo, tinham a ciência e o adequado debate acerca dessa ação e da saga que ela iniciaria.

No ano de 2005, foi constituída a Comissão Universidade para os Índios (Cuia), criada pela Secretaria de Estado da Ciência, Tecnologia e Ensino Superior do Paraná (Seti), com a finalidade de coordenar o Vestibular dos Povos Indígenas.

Esse processo se apresentava num contexto caracterizado pela luta reivindicatória dos movimentos e das organizações indígenas pela efetiva institucionalização das escolas indígenas no País - nesse momento com significativo respaldo legal e normativo -, com a clara intenção de que fosse garantida a educação básica bilíngue, específica, diferenciada e intercultural nas terras indígenas, conforme já preconizava a legislação brasileira. O ensino superior se apresentava principalmente como estratégia e possibilidade de formação dos professores índios para as escolas indígenas, dada a perspectiva de ampliação da oferta dos anos finais do ensino fundamental nas aldeias.

Decorrente dos processos de escolarização conquistados nas duas últimas décadas pelas sociedades indígenas no Brasil, o ensino superior público vem se tornando, muito recentemente, uma das pautas reivindicatórias do movimento indígena nacional. A universidade, como potencial e institucional espaço de produção e socialização do conhecimento acadêmico-científico e da constituição da inteligência nacional, torna-se alvo de direito e lugar a ser alcançado e ocupado pelos povos indígenas como sujeitos históricos e epistêmicos.

Todavia, a presença dos índios na universidade pública oportuniza ainda mais a manifestação das contradições, dos paradoxos e das incoerências que nela residem e a constituem, fundamentalmente, a partir das estratégias de ingresso e de permanência desses sujeitos no ambiente universitário. É nele que passam a se constituir e identificar como estudantes indígenas universitários - categoria emblemática, uma vez que se forja a partir de relações sociais marcadas por interações, intercâmbios, resistências, resiliências, ocultamentos, negações e afirmações.

As experiências de ensino superior iniciadas como política pública nas IES estaduais do Paraná a partir do ano de 2002, e expressivamente 
assumidas por outras universidades públicas no País nessa mesma década, revelaram que o conhecimento acadêmico produzido na universidade pelos estudantes e pesquisadores indígenas passa a ser estratégico para a afirmação cultural e política dos grupos étnicos aos quais pertencem, assim como para o desenvolvimento das suas comunidades.

Contudo, o ingresso e a permanência dos indígenas no espaço universitário e urbano (no caso daqueles que passam a residir nas cidades) tornam-se desafiadores para esses sujeitos, que passam a aprender, a vivenciar e a intercambiar diferentes perspectivas, concepções e experiências, provocando e sendo por elas provocados a refletir sobre sua identidade étnica.

As reflexões realizadas acerca desse recente fenômeno possibilitaram a compreensão de que a permanência desses acadêmicos na universidade encontra-se vinculada às suas possibilidades e estratégias em manter a dupla pertença que os caracteriza como indígenas e, simultaneamente, estudantes universitários, ou seja, mediante a efetivação de seu duplo pertencimento acadêmico e étnico-comunitário.

Contribuem para essas análises as referências, as matrizes e os conceitos no campo da educação, da sociologia e da antropologia. Fundamenta essencialmente esse debate a compreensão do conceito relacional de cultura e sociedade, entendendo que esta última é composta por múltiplas culturas que mantêm relações umas com as outras, envolvendo conflitos, exclusões, inclusões, trocas, assim como diferenças, desigualdades e ambiguidades. Descarta-se, dessa forma, a ideia de cultura originária ou autóctone, isenta ou neutra de mácula da presença de instituições coloniais, buscando retirar as coletividades indígenas de um amplo esquema dos estágios evolutivos da humanidade e passando a situá-las na contemporaneidade e em um tempo histórico múltiplo e diferenciado (Pacheco de Oliveira, 1999).

Essa concepção de cultura orienta-se pela antropologia histórica presente nos estudos de João Pacheco de Oliveira (1999), inspirada pela antropologia política, e nos estudos das sociedades complexas fundamentados nas reflexões de Eric R. Wolf (Feldman-Bianco, Ribeiro, 2003), bem como na compreensão sobre os grupos étnicos e as fronteiras étnicas encontradas nas referências de etnicidade de Fredrik Barth (1998) e, por fim, parametrada pelas reflexões sobre identidade étnica e reconhecimento marcadas pela etnologia indígena de Roberto Cardoso de Oliveira (2006).

Essas reflexões orientam para a superação da idealização da cultura indígena presente não somente nos clássicos da etnologia brasileira, mas também nos livros didáticos, no cinema, na literatura, entre outros, instigando ampliar sua compreensão à correspondente abertura analítica para sistemas regionais multissocietários e multilinguísticos, no contraditório contexto capitalista.

Esses fundamentos possibilitam a compreensão do acadêmico indígena não como representante de uma cultura que resiste e é refratária às históricas transformações sociais e culturais, mas, ao contrário, como sujeito pertencente a um grupo étnico que já sofreu modificações históricas atravessadas pelos constantes e intensos contatos com as sociedades não indígenas, principalmente no contexto do desenvolvimento capitalista, mas 
que evidencia (ou oculta) marcas de sua identidade étnica características do seu grupo de pertença.

Assim, o sujeito acadêmico indígena encontra-se articulado às suas redes de parentesco, as quais orientam a organização sociocultural, econômica e política das sociedades Kaingang e Guarani no Paraná, considerando as especificidades próprias de cada um desses grupos étnicos e da constituição histórica de cada uma das terras indígenas.

Articular as referências conceituais ora apresentadas com a compreensão da existência dos faccionalismos familiares nas terras indígenas (principalmente nos territórios Kaingang) é de suma importância para orientar a caracterização e reflexão sobre o circuito de trabalho indígena que passa a se renovar com a presença desses sujeitos. As manifestações dos sujeitos entrevistados foram fundamentais para se compreender o sentido desse circuito para eles, sendo essa uma provocadora reflexão a ser conduzida pelas IES públicas envolvidas com essa temática.

\section{Os estudantes indígenas universitários: sujeitos de duplo pertencimento}

A pesquisa documental realizada expôs alguns dados e fenômenos que marcam as trajetórias percorridas pelos indígenas no ensino superior. Nas sete edições do vestibular específico, realizadas no período de 2002 a 2008, foram registradas 688 inscrições efetuadas por 488 candidatos indígenas, apontando um significativo número de índios que prestam esse concurso por diversas vezes em diferentes cursos, conforme Gráfico 1 a seguir.

Esse fenômeno se evidencia ainda mais ao se demonstrar as recorrências na participação dos candidatos inscritos, uma vez que muitos deles se inscrevem nos vestibulares específicos mesmo matriculados e já frequentando outros cursos de graduação.

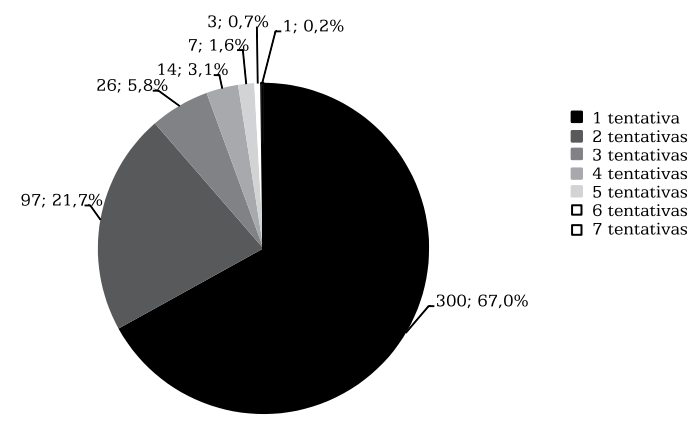

Gráfico 1 - Demonstrativo do Número de Inscrições nos Vestibulares Específicos por Candidato com Respectivo Percentual de Tentativas Fonte: Amaral, 2010.

Dos 148 candidatos que fizeram sua dupla ou até sétupla inscrição nos vestibulares específicos, 33 (22\%) foram aprovados e efetuaram 
posteriormente novas tentativas em cursos e IES semelhantes ou distintos. Alguns destes chegaram a se matricular nos cursos e IES escolhidos, porém, neles não permanecendo.

Os percursos feitos pelos candidatos indígenas ao longo das sete edições dos vestibulares específicos podem revelar fenômenos ainda não percebidos e não compreendidos oficialmente, tais como: a sua expectativa em relação ao evento vestibular dos povos indígenas; o seu nível de compreensão sobre a escolha do curso e da IES pretendida; a relação entre os candidatos e as lideranças indígenas; as fragilidades escolares evidenciadas por meio das avaliações no vestibular; o nível de satisfação e desempenho com o curso frequentado (quando o candidato já é acadêmico), entre outros.

Destaca-se que, das 189 vagas disponibilizadas pelas IES estaduais, 173 candidatos indígenas foram aprovados e 139 efetivaram sua matrícula. Do universo de matriculados, 76 deles permaneciam vinculados às respectivas instituições de ensino até o período de realização da pesquisa (setembro de 2008), 61 evadiram e dois faleceram. Do universo de 51 acadêmicos indígenas matriculados no período de 2002 a 2004, sete deles se formaram até o ano de $2007(13,7 \%)$ e oito se preparavam para sua formatura até o final do ano de 2008 (15,6\%), totalizando 15 indígenas concluintes (29,4\%). Ressalta-se, contudo, um significativo índice de evasão de acadêmicos indígenas, totalizando uma média de 44\% dos alunos ingressos pelo vestibular específico.

Cumpre destacar que, no que se refere à dimensão acadêmica, as IES estaduais que apresentam menor índice de evasão são as mesmas que institucionalizaram processos de acompanhamento dos estudantes indígenas, conforme se constata no Gráfico 2.

Verifica-se também que o curso que registra o maior número de estudantes evadidos é o de Pedagogia, o que instiga a problematização sobre: a sua organização curricular nas diferentes IES, as expectativas dos acadêmicos indígenas evadidos acerca desse curso, as possíveis influências na oferta dos cursos de magistério indígena pela Secretaria de Estado da Educação (SEED), nesse contexto, entre outras reflexões.

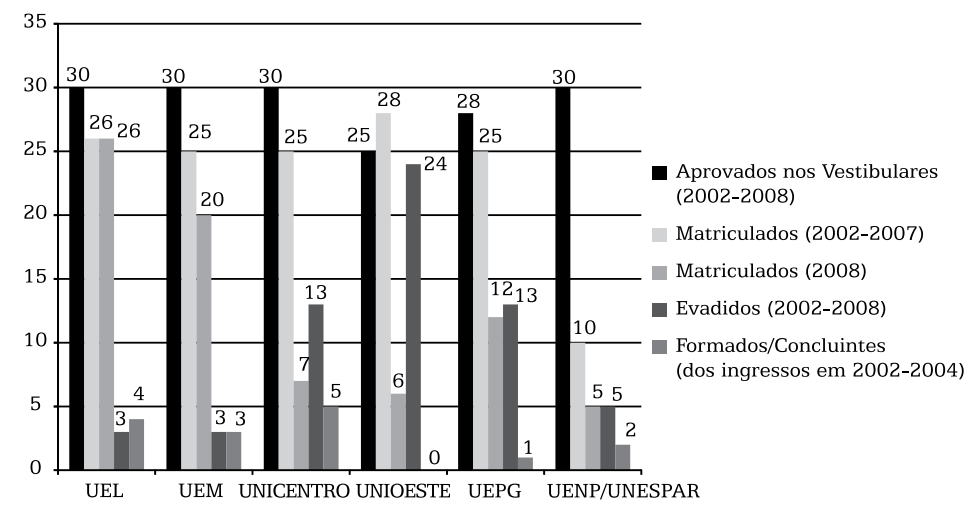

Gráfico 2 - Demonstrativo do Número de Estudantes Indígenas Aprovados nos Vestibulares Específicos, Matriculados, Evadidos e Formados/Concluintes, por IES

Fonte: Amaral, 2010. 
Constata-se que, dos 76 estudantes indígenas matriculados no ano de 2008, 35 deles pertencem a cursos de licenciatura (área da educação), representando $46 \%$ do universo total de matrículas ativas no referido período. De todos os 76 matriculados, 22 estão vinculados a cursos da área da saúde, representando 29\% do universo. Os demais 19 estudantes indígenas matriculados (25\% do total) estão vinculados a cursos das áreas de Ciências Sociais Aplicadas (Direito, Administração, Serviço Social e Secretaria Executivo), de Comunicação Social e de Agronomia.

A partir dos relatos dos acadêmicos indígenas entrevistados, pôde-se caracterizar e analisar o seu pertencimento acadêmico, considerando aspectos como: a referência da escolarização básica para a sua formação acadêmica; as precárias condições materiais e financeiras para garantir sua permanência na universidade e no meio urbano; os limites e as iniciativas de acompanhamento institucional pelas IES; os preconceitos e as experiências de interculturalidade vivenciadas no ambiente acadêmico; e o sentimento de estrangeirismo na univer-cidade.

Por pertencimento étnico-comunitário compreendem-se todas as relações sociais, afetivas, culturais, econômicas e políticas estabelecidas entre os estudantes universitários Kaingang e Guarani com os membros de sua parentela (pais, avós, esposo(a), filhos(as), genros, noras) e com os demais membros da terra indígena na qual possuem vínculo direto de residência. Também com aqueles que residem em outras terras indígenas (no Estado do Paraná ou em outros Estados brasileiros), os quais pertencem à sua rede de parentesco ou de vinculação étnica, evidenciando a organização de famílias extensas e entrelaçadas (Clastres, 1974; Mabilde, 1983; Fernandes, 2003; Mello, 2006).

A manutenção da pertença dos estudantes indígenas universitários à sua rede de parentesco, ao seu grupo étnico e à terra indígena de referência pode representar a sua permanência, afirmação ou negação junto às relações faccionais e de poder nelas existentes.

O conceito de pertencimento étnico-comunitário pôde também ser caracterizado e analisado por meio dos relatos dos entrevistados, a partir de aspectos como: a participação da comunidade no ingresso e na permanência dos estudantes indígenas na universidade; a inserção e o envolvimento dos acadêmicos indígenas no circuito de trabalho indígena intra ou interaldeias durante e/ou após a conclusão do curso; e o sentimento de estrangeirismo existente entre os estudantes indígenas e sua comunidade de origem.

A articulação entre o pertencimento acadêmico e étnico-comunitário desses acadêmicos passa a ser constatada a partir de três elementos sínteses, os quais passam a ser definidores dessa perspectiva, sendo: a afirmação de sua identidade como sujeito indígena; o acesso e a socialização dos conhecimentos acadêmicos; e o nível e a frequência de relacionamento com a comunidade indígena.

O primeiro elemento síntese pode ser evidenciado por meio da significativa potencialização do orgulho e da autoafirmação étnica pelo estudante indígena, ou seja, em reconhecer-se e gostar de ser índio, sendo 
esse um reflexo da vivência no ambiente acadêmico e na aldeia. Esse orgulho se revela nas entrevistas na medida em que os próprios sujeitos se reconhecem persistentes no seu propósito (ou mesmo de sua família e/ ou comunidade) de continuar estudando e acessando mais conhecimentos.

\begin{abstract}
Ah, na verdade, para mim, eu me sinto mais índio ainda. [...] Aí o pessoal fala: -Nós, na verdade, nós somos índios, né? Aí, é uma palavra geral, que a gente fala. Nós somos índios. E aí, como pessoa, não tem como a gente fugir de ser índio. Eu falo para eles que eu me orgulho de ser índio e por estar numa universidade dessa aqui fazendo o que eu sempre quis. E às vezes, existem pessoas que escondem que são índias. Eu chego a me orgulhar de ser índio e de chegar aqui da maneira que eu cheguei, sendo índio. (Acadêmico Kaingang, matriculado inicialmente no curso de Medicina e, depois, transferido para o curso de Artes, na Universidade Estadual de Londrina - UEL).
\end{abstract}

As manifestações apresentadas pelos acadêmicos indígenas revelam o conceito de identidade étnica associado à noção de reconhecimento (autorreconhecimento e o reconhecimento pelo outro), a partir do contraste com o outro (indígena e/ou não indígena), o que Cardoso de Oliveira (2006, p. 22) conceituaria por identidade contrastiva.

Ao revisitar suas análises acerca do conceito de identidade étnica, esse autor afirma a sua associação ao campo da etnicidade e aos estudos sobre a moral do reconhecimento. Situa, dessa forma, a questão da identidade étnica, do autorreconhecimento indígena e do respeitoso reconhecimento indígena pelos não indígenas no campo que denominou como etnoética, ou seja, da existência da "dimensão ética ou moral no trato das relações interétnicas no âmbito da formulação e execução de políticas públicas dirigidas às etnias indígenas" (Cardoso de Oliveira, 2006, p. 46).

Essa perspectiva contribui para a compreensão de como as identidades étnicas indígenas, em diferentes contextos sociais, políticos e culturais, passam a ser invisibilizadas, evidenciadas, assimiladas, manipuladas e assumidas pelas políticas públicas afetas aos povos indígenas e pelos próprios e diferentes grupos étnicos. Para o autor, a assunção da identidade étnica pelos sujeitos e povos indígenas está associada à conquista e ao reconhecimento de sua condição cidadã e, por consequência, da possibilidade de uma vida ética de direitos de cidadania (Cardoso de Oliveira, 2006, p. 54-55).

A afirmativa assunção de sua identidade étnica pelos acadêmicos indígenas pode revelar e indicar aspectos de efetividade do direito conquistado ao acessar, permanecer e concluir o ensino superior público. O crescente respeito e a afirmação identitária indígena assumida e influenciada a partir da elevação dos níveis de escolarização, principalmente das classes etárias indígenas mais jovens, passa a denotar a constituição de uma moderna situação interétnica, conforme contextualiza Cardoso de Oliveira (2006, p. 52-53), sendo um dos reflexos do movimento pan-indígena difundido nas Américas a partir da década de 1970:

Seja no México, seja no Brasil - países nos quais pude realizar observações etnográficas -, observa-se um claro processo de "modernização", a começar pela presença das novas gerações, que, em 
algumas comunidades, alcança níveis elevados de alfabetização, fato que entendo ser um bom indicador do que é ser um índio moderno. Através dessa alfabetização surge uma elite indígena [...] quando se observa nessas populações uma luta não apenas por ganhos materiais, mas também pela cidadania, que bem poderia ser traduzida por busca de respeitabilidade a si mesmos, de seus valores e de suas formas de ver o mundo. [...] Claro que não se pode generalizar esse efeito virtuoso do movimento indígena em todas as etnias e, nem mesmo, em todas as pessoas membros desses povos originais. Todavia, as observações que têm sido feitas por etnólogos e indigenistas permitem afirmar que os setores mais modernos desses povos - que em termos de gerações seriam as classes etárias mais jovens - vêm assumindo aquilo que se poderia chamar uma ideologia de crescente autorrespeito.

\section{A afirmação da identidade desse estudante universitário como sujeito} indígena, dessa forma, pode estar intimamente associada ao acesso e à socialização dos conhecimentos acadêmicos aprendidos na universidade, sendo este o segundo elemento síntese que caracteriza o duplo pertencimento a que se refere este trabalho. A aprendizagem desses conhecimentos também é compreendida como um dos significativos aspectos que caracterizam esse novo e diferente mundo acadêmico, evidenciado pelos entrevistados. Referem-se aos conhecimentos técnicos, científicos e acadêmicos buscados, socializados e aprendidos no ensino superior, constituindo o cerne da existência da universidade e da escola.

Contribuiu. A gente dá mais valor naquilo que a gente é e que a gente vê que a gente tem mais força, a gente vê... Você descobre que tem muitas possibilidades de lutar por aquilo que você quer e de trazer benfeitorias para a comunidade. Não só para a sua, mas para as outras também. Eu acho assim, para ver, tentar uma vida melhor e amenizar um pouco o sofrimento dos índios. É isso. ${ }^{1}$ (Acadêmica Guarani, matriculada no curso de Medicina da UEL).

Eu consegui manter esse vínculo com a ideia deles. Porque muitos professores e pedagogos com quem eu conversei dão uma ideia para nós para colocar nas nossas reservas, porque a gente sempre está procurando, como pedagoga, conhecer mais. É conversar com os não indígenas, o que pode ser mudado, como a gente tem que colocar na nossa escola indígena. Tem muitas coisas dos não indígenas que a gente pode aproveitar e colocar para eles lá, da nossa forma indígena, o que é bem proveitoso. [...] Eu acho que ajudou bastante [identificar-se como estudante na comunidade]. Porque ali, a gente está buscando conhecimento, novas metodologias para serem colocadas em prática para eles lá. [...] Eu acho que é o contato que a gente sempre está mantendo com os não indígenas, o contato que a gente tinha com os indígenas. (Pedagoga Kaingang, formada pela Universidade Estadual de Ponta Grossa - UEPG).

Apesar da importância da aprendizagem desses novos conhecimentos para os acadêmicos indígenas, adverte-se, porém, que esse movimento raramente é de mão dupla, isto é, os indígenas parecem, para a academia, não ter nada sabido ou a ensinar. Ciência e cultura são, nesse paradigma predominante, ainda que não explicitado, patrimônio da universidade e somente dela.

Nesse sentido, evidenciam que as maiores dificuldades encontradas para manter seu duplo pertencimento se encontram na relação com e na

\footnotetext{
${ }^{1}$ Resposta da entrevistada ao ser questionada sobre o que contribuiu ou dificultou para ela se sentir mais indígena ao identificar-se como estudante universitária tanto na aldeia quanto na universidade.
} 
${ }^{2}$ Cada acadêmico indígena recebe atualmente uma bolsa auxílio no valor de $\mathrm{R} \$ 400,00$, com acréscimo de $50 \%$ no seu valor para os que comprovem a guarda de filhos, independentemente do número de dependentes. Importante ressaltar que dos sete estudantes entrevistados, quatro deles possuem responsabilidades paternas ou maternas, tendo entre três a quatro filhos. Revelam que o valor da bolsa é insuficiente para suprir as despesas pessoais e acadêmicas decorrentes de sua permanência e de sua família na cidade. universidade, uma vez que sua pertença familiar e étnico-comunitária é o que originalmente os identificam e os sustentam como sujeitos indígenas. Reconhecem a universidade como um lugar em que muitos deles encontram-se institucionalmente determinados diante do objetivo de estudar, haja vista as regras, normas e disciplinas que precisam cumprir para se manterem na condição de estudante universitário, fundamentalmente de bolsistas. ${ }^{2}$

Outrossim, ao adquirirem mais conhecimentos credenciam-se como estudantes indígenas em potencial na universidade, ampliando sua leitura de mundo e sentindo-se academicamente mais fortalecidos e etnicamente mais identificados.

Entre os limites mais ressaltados pelos entrevistados, a referência à frágil escolaridade básica é um dos mais contundentes. Ressalta-se que essa fragilidade é revelada pelos entrevistados principalmente se comparado o seu desempenho ao dos seus colegas não indígenas dos cursos que estão frequentando. Destaca-se ainda a contundência dessa manifestação pelos entrevistados cuja autoestima étnica também é por eles apresentada de forma fragilizada, diferentemente dos acadêmicos cuja identidade étnica proclama-se de forma afirmativa.

A relatada fragilidade no domínio de conteúdos escolares é um dos motivos por eles apresentados para ruptura do pertencimento acadêmico, revelados pelos índices de evasão, pelo desânimo em continuar estudando e, consequentemente, pelo desejo de permanência nas aldeias, principalmente nos períodos de férias ou feriados prolongados.

\begin{abstract}
Mas tiveram alguns alunos que não quiseram mais voltar. Teve um de Cascavel que foi nas férias e não voltou mais. Mas eu acho que nem é tanto pelo vínculo com a aldeia. É a base dele, é a diferença mesmo, de não se acostumar, não gostar e não ter o conteúdo pedagógico para ficar ali, para poder entender, sabe? Nem tanto pela... Não sei, eu estou falando de mim, né? Eu acho que a comunidade não interfere. (Acadêmica Guarani, matriculada no curso de Medicina/UEL).
\end{abstract}

A indiferença, o desincentivo ou a resistência dos acadêmicos indígenas ao retorno à universidade podem apresentar a proposta do Vestibular dos Povos Indígenas como ação afirmativa na porta de entrada, via vagas suplementares, e negativa na saída da "vítima culpada por seu insucesso" pela porta dos fundos. Essa reflexão se afirma a partir da fragilidade das políticas institucionais voltadas à permanência acadêmica desses sujeitos no ensino superior, caracterizando-se ainda como um ensaio de política pública, não se tornando concretamente efetiva.

Em contraposição, na trajetória escolar de alguns dos estudantes entrevistados observa-se também que o domínio de conteúdos escolares próprios da escolarização básica associada às experiências (positivas ou negativas) realizadas nas escolas urbanas, apresenta-se como um dos elos para a manutenção dos vínculos universitários, como se eles os credenciassem para driblar os rituais e as regras da escola não indígena, entre eles, os preconceitos. 
Contudo, ao analisar a própria experiência relatada durante as entrevistas, os acadêmicos revelam e afirmam sua defesa de que toda a oferta da educação básica deve ocorrer nas escolas indígenas no interior das aldeias (desde que garantida as condições de qualidade nos processos de escolarização), o que pode vir a assegurar identidade e pertencimento étnico aos alunos indígenas.

Essas evidências instigam a reflexão sobre a importância e o papel da escola indígena em articular, na sua organização curricular, a socialização de conteúdos escolares de forma dialógica com os conhecimentos étnicos e tradicionais presentes na comunidade, possibilitando a estes últimos o seu reconhecimento, visibilidade e afirmação.

A dialogicidade e interculturalidade entre diferentes conhecimentos pautados na escola podem preparar e potencializar os estudantes indígenas ao ensino superior, seja este organizado de forma específica (tal como os cursos de Licenciaturas Interculturais iniciados recentemente em diversos Estados) ou por meio do acesso aos cursos convencionais ofertados nas universidades. Tal qual, essa perspectiva deve compor as diferentes organizações curriculares e pedagógicas dos diversos cursos de graduação e pós-graduação nas universidades.

Nessa lógica, ao evidenciar o debate acerca da especificidade da questão indígena na formação étnica nacional, Peres (2007, p. 43) expõe a afirmação de João Pacheco de Oliveira, o qual inverte o nexo que expõe a baixa escolaridade dos estudantes indígenas como a centralidade justificadora de seu frágil desempenho acadêmico e remete essa reflexão à histórica forma de organização e à natureza da universidade:

O problema das populações indígenas no que se refere ao ensino superior não é de baixa escolaridade, mas do reconhecimento e promoção de valores e visões de mundo diferenciados. Não se trata, portanto, de inclusão social apenas e sim da construção de uma outra universidade.

Apesar das dificuldades vivenciadas e relatadas pelos entrevistados, constata-se que a permanência dos estudantes indígenas na universidade e sua relação com os conhecimentos aprendidos e elaborados estão conectadas a um objetivo pessoal e coletivo assinalado pelo seu pertencimento étnico-comunitário. Esse pertencimento pode se caracterizar como elemento fundamental das políticas de ação afirmativa dos povos indígenas, bem como inspirar e potencializar a positiva teimosia, resistência e capacidade de resiliência dos acadêmicos indígenas, não permitindo que deixem de ser índios ao manterem-se estudantes universitários.

Assim, a manutenção do vínculo universitário do estudante indígena ocorre pela apropriação de conhecimentos e técnicas aprendidas e socializadas junto aos professores e acadêmicos não indígenas durante o seu processo formativo, as quais podem ser apresentadas, disseminadas e utilizadas nas aldeias. Isso se expressa como se o conjunto de conhecimentos novos aprendidos durante a graduação credenciasse os estudantes indígenas diante de suas comunidades, potencializando e 
possibilitando respostas aos problemas e às dificuldades vivenciados cotidianamente.

Do conjunto de relatos que se referem aos conhecimentos aprendidos e intercambiados na universidade, bem como aos que foram sendo estudados ao longo das trajetórias escolares e formativas dos estudantes indígenas entrevistados, pode-se sistematizar e evidenciar três diferentes distinções: os conhecimentos escolares na universidade; os conhecimentos acadêmicos na comunidade indígena; e os conhecimentos tradicionais de cada grupo étnico, guardados e reelaborados historicamente em cada aldeia ou grupo familiar.

Esses diferentes conhecimentos passam a compor o elenco formativo dos estudantes indígenas - explicitados ou ocultados por estes, pelas suas comunidades em contato com a universidade (em projetos ou eventos preparados para tal), ou mesmo pelos professores e colegas não indígenas no cotidiano dos cursos e das salas de aula. Ao referir-se aos necessários esforços a serem feitos pelos povos indígenas em construções epistêmicas diversas para as universidades, Joênia Wapichana (2007, p. 55) afirma que:

A universidade também existe lá nas comunidades. Mas o que é a universidade? É o universo de conhecimentos. E se esse universo de conhecimentos existe ali nas comunidades, ele precisa ser valorizado levar esse universo de conhecimentos indígenas para as universidades é também contribuir para a construção de um país melhor.

A manifestação da autora revela a importância de se reconhecer e compreender a universidade como espaço democrático de fronteira étnica (Barth, 1998) e/ou como zona de contato (Souza Santos, 2001) onde é possível traduzir e intercambiar conhecimentos que partem, se fundamentam e se constituem de diferentes lógicas. Segundo Cavalcante (2009, p.112), "parte da perspectiva de reconhecer que existe uma pluralidade de saberes que operam em contextos e práticas sociais próprias, e que os processos de transmissão da educação formal têm que identificar qual saber cabe para determinado contexto social".

Destarte, todos os entrevistados estabelecem uma orgânica relação entre os conhecimentos aprendidos na universidade e as necessidades, expectativas e realidades de suas aldeias e do seu grupo étnico, potencializando seu duplo pertencimento e credenciando sua futura inserção profissional na aldeia. A essa questão associa-se o terceiro elemento síntese e constituinte do que se denomina neste trabalho duplo pertencimento, referindo-se especificamente ao nível e à frequência de relacionamento dos acadêmicos indígenas com a sua comunidade de origem.

A autoidentificação como estudante indígena e seu acolhimento e permanência na universidade e na aldeia dependem, fundamentalmente, dos vínculos que esse sujeito consegue manter em ambos os espaços. Reconhece-se que o vínculo familiar e étnico-comunitário é fundamental para nutrir sentido à sua permanência acadêmica e indígena na universidade, assim como para a garantia de seu retorno à aldeia.

Observa-se, contudo, que a manutenção do duplo pertencimento do estudante indígena universitário depende da frequência e qualidade 
da relação que este sujeito estabelece com a sua família, com os demais membros da sua comunidade de origem e de seu grupo étnico. Importante ressaltar que essa relação também é mediada pelas demais condições de permanência e pertencimento acadêmico, tais como: desempenho no curso, nível de preconceito social e institucional vivenciado, relacionamento com colegas e professores não indígenas, condições financeiras, entre outras.

A significativa ausência do estudante indígena na aldeia em que mantém seus vínculos de pertencimento pode provocar indiferenças e estranhamentos locais por parte de membros da comunidade. Também, a frequente e excessiva permanência na aldeia, fundamentalmente pelos estudantes casados e pais (principalmente nos períodos de férias, feriados prolongados ou em contexto de dificuldades econômicas), pode fragilizar a sua permanência na universidade, dificultando o acompanhamento dos conteúdos escolares desenvolvidos em sala de aula.

O duplo pertencimento dos estudantes indígenas universitários pode ser mediado pela relação dos caciques e lideranças indígenas para com esses sujeitos e com a universidade. A não presença dos caciques e das lideranças indígenas no ambiente universitário e nas relações com as IES pode limitar a compreensão das comunidades indígenas sobre a realidade e os problemas vivenciados pelos estudantes indígenas, tampouco afirma seu vínculo com a comunidade e com a universidade.

O estudante indígena enfrenta uma espécie de buraco perverso de estrangeirice, na medida em que compete a ele mesmo o esforço, às vezes hercúleo, de convencer a aldeia e a família às quais continua pertencendo e também a universidade de que não é um estudante comum.

Eu me sinto. Eu estando aqui me sinto estrangeiro e estando lá me sinto estrangeiro, porque o pessoal, na verdade, vê a gente com outro olhar agora. E, às vezes, até o pessoal tira um sarro... Aqui a gente utiliza um tipo de linguagem mais elevado, assim, para poder conversar com o outro, falar com o outro. Um tipo de linguagem diferente. E lá, o pessoal já tem aquela linguagem mais puxando pro lado do caipira mesmo, o caipirão. Aí, às vezes, eu começo a falar uma palavra lá, falo uma frase inteira mais técnica mesmo, e aí o pessoal fala: - Nossa! O cara tá metido, hein, falando desse jeito aí. Mas aí, os caras me dão importância quando eu chego lá. Representa, assim, que eu estou chegando lá pela primeira vez: - Vamos chegar em casa, vamos tomar um café, vamos jogar uma bola, ali. Você chegou? Vamos pra cidade tomar um sorvete, lá, tomar uma cerveja, vamos lá?! [...] Aí, eu comecei a ficar bem visto lá em São Jerônimo. O pessoal falava: - Nossa, esse rapaz faz Medicina, e está estudando, daqui uns dias vai ser doutor. O pessoal da cidade de São Jerônimo que me conhecia, já me cumprimentava como doutor. O pessoal da aldeia também, me cumprimentava: - Nossa, está vindo o doutor ali! Já brincavam comigo, cacique e tudo. Então, isso me incentivava, acabou me incentivando muito mais em fazer Medicina. (Acadêmico Kaingang, matriculado inicialmente no curso de Medicina e, depois, transferido para o curso de Artes da UEL)

Igualmente, a frequente presença dos caciques e das lideranças indígenas na universidade possibilitaria a definição e operacionalização de ações de extensão e pesquisa nas comunidades, credenciando e 
visibilizando os estudantes indígenas perante as aldeias e a universidade. Por outro lado, o reconhecimento local e mesmo institucional dos acadêmicos indígenas pode ou não ocorrer, dependendo das relações políticas e faccionais em cada aldeia e da rede de relações políticas interétnicas estabelecidas em cada Estado e para cada grupo étnico.

Fundamental, dessa forma, é a compreensão das relações existentes entre os acadêmicos indígenas (situados e vinculados em sua rede de parentesco) e os caciques e demais lideranças indígenas, mediadas pelos diferentes interesses, posições e aspirações de poderes locais e étnico-territoriais ora estabelecidos. A presença do acadêmico indígena, bem como do futuro e novo profissional nas aldeias pode ampliar as relações políticas internas para além do cacique, provocando tensões e reorganizações nas posições atualmente definidas, uma vez que ele próprio possa ser reconhecido como uma nova liderança, dependendo do perfil e dos vínculos parentais e faccionais a que pertence.

A titulação alcançada pode potencializar a atuação dos caciques e das lideranças que podem contar com conhecimentos técnicos e científicos a serviço das suas comunidades e, ao mesmo tempo, receber o apoio, a aliança ou a oposição do novo profissional que retorna à aldeia, dependendo do tronco ou grupo familiar a que pertence, bem como do espaço político-profissional que venha a ocupar na aldeia. Dessa forma, a manutenção do duplo pertencimento pelo acadêmico indígena pode contribuir para a compreensão e superação dos sentimentos de duplo estrangeirismo que, via de regra, se manifestam na sua relação com a universidade e com a sua comunidade de origem.

Olha, no início foi uma coisa assim que as pessoas ficaram um pouco, já pensando se ia dar certo ou não, mas depois eles conseguiram ver que... Eles não acreditavam que eu ia chegar aqui, achavam que ia desistir, mas agora eles veem que... Eu acredito que sentem até orgulho. Porque, eu, por exemplo, a minha família, eles têm um posicionamento, lá, de liderança na comunidade. Eu tive uma passagem breve, mas tive... Então, tenho umas divergências políticas, você tem críticas, mas a maioria me vê como, sei lá, solução dos problemas deles... Eu saio no Apucaraninha, hoje... Se eu sair na rua lá, todo mundo pergunta: - Aconteceu isso, como a gente pode agir, de que forma vamos fazer isso, perguntar como é que estão os projetos. (Acadêmico Kaingang, matriculado no curso de Direito na Universidade Estadual de Maringá - UEM)

Ao referir-se sobre o reduzido número de indígenas ingressantes e concluintes no ensino superior e o papel das universidades nesse contexto, Lúcio Flores (2007, p. 43-46), membro da Coordenação das Organizações Indígenas da Amazônia Brasileira (Coiab), afirma que:

[...] os índios que saem de suas aldeias para estudar sofrem duas formas de desprezo: são acusados pelos seus próprios parentes de abandonarem seu povo, enquanto os brancos que moram nas cidades mandam que voltem para seus lugares de origem, de onde não deviam ter saído. [...] existe uma dificuldade de entender o que o índio fará depois de concluir seu curso universitário: será que ele retornará ao seu povo? Num momento em que os povos indígenas estão mais fortalecidos, 
a universidade pode constituir-se numa grande parceira. [...] Essas dificuldades nos levaram a entender que o desafio era muito maior do que sair solitariamente, que era preciso criar um grupo que fosse mais forte, que pensasse um pouco mais sobre a possibilidade de acesso à universidade.

Nessa lógica, entende-se que o debate interno nas comunidades indígenas e nas universidades sobre a política pública de ingresso e permanência no ensino superior deve reconhecer, compreender e, a partir das trajetórias já trilhadas, vivenciadas e protagonizadas pelos estudantes indígenas, avançar na centralidade histórica e necessária para compor o presente e o futuro desses sujeitos.

\section{Considerações finais}

O presente trabalho explicita que uma das marcas identitárias dos acadêmicos indígenas reside na sua capacidade de duplo pertencimento acadêmico e étnico-comunitário, buscando permanentemente superar as fragilidades impostas pelas precárias condições econômicas, pela limitada formação escolar básica, pela incipiente organização institucional das IES públicas, pelas perversas manifestações de preconceito vivenciadas, pela pedagogia universitária despreparada para as ações afirmativas, entre outros aspectos.

O duplo pertencimento também se revela na sua intensa e dialética jornada para superar a condição de estrangeiro, ao mesmo tempo que reconhece que o é, principalmente no espaço universitário e, em diversas situações, também em suas comunidades de origem.

Outra referência fundamental que caracteriza a possibilidade do duplo pertencimento refere-se à importância desses sujeitos em acessar, aprender, produzir e socializar conhecimentos acadêmicos vinculados, organizados e disseminados pelas mais variadas disciplinas e cursos de graduação e pós-graduação, sendo estes parte do patrimônio público que é deles e de suas comunidades por direito. Os conhecimentos tradicionais indígenas podem ser (re)conhecidos e investigados por esses sujeitos, propondo-se ao permanente diálogo com os sábios e os mais velhos de suas comunidades, bem como com os outros conhecimentos científicos produzidos por diversos especialistas na universidade.

Revela-se que estar na universidade na condição de acadêmico indígena também pressupõe debater acerca da incipiente e tímida interculturalidade nos processos formativos que envolvem o ensino, a pesquisa e a extensão, na graduação e na pós-graduação, bem como nos mais diversos setores que constituem as IES. Entende-se que a tarefa de encharcar de interculturalidade a universidade pública, gratuita e de qualidade não seja somente de responsabilidade do estudante indígena, mas sim desafio institucional dos gestores das políticas de ensino superior.

Portanto, o desafio proposto é o de anunciar a afirmativa possibilidade da permanência dos estudantes indígenas na universidade como parte 
de seu processo formativo, bem como as estratégias por eles e por suas comunidades definidas para tal. Dessa forma, é fundamental que as lideranças e comunidades indígenas tomem o espaço acadêmico e universitário como seu lugar de pertença e de direito, inspirando e provocando a universidade pública a compreender as especificidades e diversidades linguísticas, socioculturais, cosmológicas e políticas indígenas, bem como evidenciando as realidades de precariedade e de desigualdades sociais e econômicas que atingem as terras indígenas.

A compreensão do esforço de equilibrismo exercido cotidianamente por esses sujeitos na manutenção do seu duplo pertencimento - manifestado pela sua afirmativa permanência na universidade - deve instigar a problematização, as intervenções e os investimentos institucionais necessários para que esse processo formativo seja coerente e efetivamente assumido como política de Estado. Pressupõe superar a assunção individual principalmente dos insucessos nessa trajetória pelo estudante indígena. Nessa lógica, o reconhecimento do duplo pertencimento e do seu exercício advém, sobretudo, do esforço institucional em criar condições pedagógicas e estruturais para que esse estudante continue se reconhecendo indígena e acadêmico.

\section{Referências bibliográficas}

AMARAL, Wagner R. As trajetórias dos estudantes indígenas nas Universidades Estaduais do Paraná: sujeitos e pertencimentos. 2010. Tese (Doutorado em Educação) - Universidade Federal do Paraná. Curitiba, 2010.

BAIBICH, Tânia M. Fronteiras da identidade: o auto-ódio tropical. Curitiba: Moinho do Verbo, 2001.

BARTH, F. Grupos étnicos e suas fronteiras. Bergen, Oslo: Universitetsforlagets, 1969. In: POUTIGNAT, P.; STREIFF-FENART, J. Teorias da etnicidade. Seguido de Grupos étnicos e suas fronteiras, de Fredrik Barth. São Paulo: Fundação Editora da Unesp, 1998.

CAPELO, Maria Regina C.; AMARAL, Wagner R. Quando a diferença faz a diferença: a presença de índios na Universidade Estadual de Londrina. Educação e Linguagem, v. 7, n. 10, p.168-190, 2004.

CARDOSO DE OLIVEIRA, Roberto. Caminhos da identidade: ensaios sobre etnicidade e multiculturalismo. São Paulo: Ed. Unesp; Brasília: Paralelo 15, 2006.

CAVALCANTE, Márcio R. V. O que há de perspicácia e o que há de ingenuidade nos motivos apresentados pelos indígenas sobre a escola? 
Tabebuia: índios, pensamento e educação, Belo Horizonte, v. 1, n. 1, p. 104-113, 2009.

CLASTRES, Pierre. La société contre l'Estat. Paris: Minuit, 1974.

FELDMAN-BIANCO, Bela; RIBEIRO, Gustavo L. (Orgs.). Antropologia e poder: contribuições de Eric R. Wolf. Brasília: Ed. UnB, 2003.

FERNANDES, Ricardo C. Política e parentesco entre os Kaingang: uma análise etnológica. 2003. Tese (Doutorado em Antropologia Social) Universidade de São Paulo, 2003.

FLORES, L. Ação afirmativa e direitos culturais diferenciados: as demandas indígenas pelo ensino superior. In: LIMA, A. C. S.; BARROSO-HOFFMANN, M. (Orgs.). Seminário Desafios para uma Educação Superior para os Povos Indígenas no Brasil: políticas públicas de ação afirmativa e direitos culturais diferenciados. Rio de Janeiro: Museu Nacional, Laced, 2007.

MABILDE, P. F. A. B. Apontamentos sobre os indígenas selvagens da nação coroados dos matos da Província do Rio Grande do Sul (18361866). São Paulo: Ibrasa, FNPM, 1983.

MELLO, Flávia C. Aetchá nhanderukuery karai retarã: entre deuses e animais: xamanismo, parentesco e transformação entre os Chiripá e Mbyá Guarani. 2006. Tese (Doutorado em Antropologia Social) Universidade Federal de Santa Catarina, Florianópolis, 2006.

PACHECO DE OLIVEIRA, João. Ensaios de Antropologia Histórica. Rio de Janeiro: Ed. UFRJ, 1999.

PERES, Sidnei C. Ação afirmativa e direitos culturais diferenciados: as demandas indígenas pelo ensino superior [mesa redonda]. In: LIMA, A. C. S.; BARROSO-HOFFMANN, M. (Orgs.). Seminário Desafios para uma Educação Superior para os Povos Indígenas no Brasil: políticas públicas de ação afirmativa e direitos culturais diferenciados. Rio de Janeiro: Museu Nacional, Laced, 2007.

PEREZ, L. La identidad reprimida. Buenos Aires: Galerna, 1968.

SOUZA SANTOS, Boaventura. Os processos de globalização:

globalização, fatalidade e utopia? Porto: Afrontamento, 2001.

WAPICHANA, J. Ação afirmativa e direitos culturais diferenciados: as demandas indígenas pelo ensino superior [mesa redonda]. In: LIMA, A. C. S.; BARROSO-HOFFMANN, M. (Orgs.). Seminário Desafios para uma Educação Superior para os Povos Indígenas no Brasil: políticas públicas 
de ação afirmativa e direitos culturais diferenciados. Rio de Janeiro:

Museu Nacional,Laced, 2007.

Wagner Roberto Amaral, doutor em Educação pela Universidade Federal do Paraná (UFPR), é professor do Departamento de Serviço Social da Universidade Estadual de Londrina (UEL), vinculado ao Núcleo de Estudos e Pesquisas em Gestão de Políticas Sociais dessa instituição. wbetoamaral@hotmail.com

Tânia Maria Baibich-Faria, doutora em Psicologia Social pela Universidade de São Paulo (USP), é professora do Programa de Mestrado e Doutorado da Universidade Federal do Paraná (UFPR).

tbaibich@terra.com.br

Recebido em 18 de abril de 2011.

Aprovado em 18 de abril de 2012. 